\title{
Association Between Hypoalbuminemia, Degree of Proteinuria, and Lupus Nephritis Class: A Single-Center Cross-sectional Biopsy Study
}

\author{
Ngoc Nguyen Thi ${ }^{1}$, Dien Tran Minh ${ }^{1}$, Huong Nguyen Thu ${ }^{1}$, Phuong Luong Thi ${ }^{2}$, Nam Thai Thien ${ }^{1}$, Diep \\ Pho Hong ${ }^{1}$, Kien Nguyen Trung ${ }^{3,4}$, Tien Tran Viet ${ }^{3,4}$, Quyet Do $^{3}$ and Thang Le Viet ${ }^{3,4, *}$ \\ ${ }^{1}$ Vietnam National Hospital of Pediatrics, Ha Noi, Vietnam \\ ${ }^{2}$ Ha Noi Medical University, Ha Noi, Vietnam \\ ${ }^{3}$ Vietnam Military Medical University, Ha Noi, Vietnam \\ ${ }^{4}$ Military Hospital 103, Ha Noi, Vietnam \\ "Corresponding author: Military Hospital 103, Vietnam Military Medical University, Ha Noi, Vietnam. Email: lethangviet@yahoo.co.uk
}

Received 2021 February 25; Accepted 2021 March 02.

\begin{abstract}
Background: The current study intended to determine whether serum albumin level and urine protein/creatinine rate (uPCR) are appropriate predictors of severe lupus nephritis in childhood-onset SLE.

Objectives: Following a cross-sectional single-center design, 85 LN children referred to the National Children Hospital, Ha Noi, Viet Nam, from 6/2019 to 6/2020 were recruited. Renal biopsy was performed for all participants.

Methods: Following a cross-sectional single-center design, 85 LN children referred to the National Children Hospital, Ha Noi, Viet Nam, from 6/2019 to 6/2020 were recruited. Renal biopsy was performed for all participants.

Results: The mean SLEDAI score of all patients was 14.69. The proportion of patients with high and very high SLEDAI was 61.2 and $17.6 \%$, respectively. The mean concentration of serum albumin was $28.55 \mathrm{~g} / \mathrm{L}$, and the proportion of decreased albumin concentration was $55.3 \%$. The median uPCR was $446.6 \mathrm{mg} / \mathrm{mmol}$ in which $76.5 \%$ of values were $\geq 200 \mathrm{mg} / \mathrm{mmol}$. Pathological morphology of LN class from I to VI was observed in $0 \%, 17.6 \%, 37.6 \%, 37.6 \%, 7.1 \%$, and $0 \%$, respectively. Serum albumin level and uPCR presented the predictive value for severe and active LN (class IV and V); (AUC: $0.725 \mathrm{P}<0.001$ for both).

Conclusions: Serum albumin and UPCR were appropriate predictors for severe and active LN in Vietnamese children.
\end{abstract}

Keywords: SLE, Pediatric Lupus Nephritis, Serum Albumin, Urine Protein/Creatinine Rate, Pathological Morphology

\section{Background}

Systemic lupus erythematosus (SLE) is a multisystemic disease with diverse pathogenesis and clinical presentations with considerable comorbidities and significant drug side effects (1-3). Understanding the root cause of SLE is still incomplete. Evidence suggests that abnormalities in the genetic, hormonal, immune system and environmental factors are related to the pathogenesis of SLE (4-6). Childhood-onset SLE (CSLE) is an SLE onset before the age of 18 , which is associated with more serious multi-organ dysfunction compared to that of adults (6). The common hematological manifestations of cSLE are hemolytic anemia, thrombocytopenia, leukopenia, and lymphopenia (7).

SLE is a chronic inflammatory disease that affects the kidneys in about $50 \%$ of adult patients and about $80 \%$ of children (8-10). Lupus nephritis is one of the most common manifestations of SLE patients. It often leads to end-stage kidney disease (ESRD) for both adults and children (8). In patients with cSLE, not only clinical events are often more severe, but also multi-organ dysfunction is more common than SLE in adults (11-14). There is no publication concerning the demographic, clinical, and pathological features of pediatric LN and their correlations in Viet Nam. Therefore, the present study intended to evaluate some clinical and laboratory manifestations of Vietnamese pediatric patients with biopsy-proven LN class according to the International Society of Nephrology and the Renal Pathology Society (ISN/RPS) 2003 classification (revised in 2018), renal pathological activity, and chronicity index in children with LN.

\section{Objectives}

The current study intended to determine whether serum albumin level and urine protein/creatinine rate (uPCR) are appropriate predictors of severe lupus nephritis in childhood-onset SLE. 


\section{Methods}

\subsection{Study Design}

The current cross-sectional, single-center-based study was performed at the Nephrology and Dialysis Department in National Children Hospital, Ha Noi, Viet Nam, from $6 / 2019$ to 6/2020. A total of 85 children younger than 18 with presented clinical features of LN were recruited. SLE was diagnosed using the Systemic Lupus Erythematosus International Collaborating Clinics (SLICC) criteria for SLE classification (15). We defined LN as the 24-hour urinary protein $\geq 500 \mathrm{mg}$ (or uPCR $\geq 0.5 \mathrm{mg} / \mathrm{mmol}$ ) or the appearance of red blood cell casts in urine $(>5 \mathrm{RBC} / \mathrm{HPF}$ by manual analysis of the urine sediment) (16). Participants with other comorbidities, history of kidney transplantation, those receiving hemodialysis, primary neoplastic conditions, and inconclusive results were excluded.

\subsection{Clinical and Laboratory Dataset}

For each participant, the following laboratory data were collected: full blood count, immuno-biological tests (blood glucose, serum albumin, serum protein, serum C-reactive protein, serum double-stranded DNA (dsDNA), and serum $\mathrm{C} 3$ and $\mathrm{C} 4$ levels. Clinical parameters (age, sex, skin lesions, rheumatism, neurological lesion, and heart lesion) were also documented for each subject. The systemic lupus erythematosus disease activity index (SLEDAI) was calculated for all patients to determine SLE activity levels (15).

Parameters of kidney lesions were collected for each of the patients as: edema, hypertension, urine analysis, urine protein/creatinine rate, estimated glomerular filtration rate (eGFR). Hypertension is defined as blood pressure higher than the 95th percentile value of healthy people of the same age and sex (17). The eGFR was calculated based on the Schwartz formula (18). An eGFR $<60 \mathrm{ml} / \mathrm{min}$ per $1.73 \mathrm{~m}^{2}$ was considered as ESRD. We defined nephrotic syndrome as proteinuria $>50 \mathrm{mg} / \mathrm{kg}$ in $24 \mathrm{~h}$ urine and serum albu$\min <30 \mathrm{~g} / \mathrm{L}$. The LN patients with proteinuria $<50 \mathrm{mg} / \mathrm{kg}$ in $24 \mathrm{~h}$ urine were classified as nephritis syndrome.

All 85 patients underwent renal biopsy. The indications of kidney biopsy were proteinuria $>500 \mathrm{mg} / 24 \mathrm{~h}$, active urine sediment ( $\geq 5$ RBC or WBC/HPF, mostly dysmorphic without evidence of infection), or rising serum creatinine $(19,20)$. Renal biopsies were done by a Trucut semi-automated renal biopsy gun. Hematoxylin and Eosin (HE), periodic acid Schiff (PAS), silver methamine, Masson's Trichrome (MT) stains were used for light microscopy. Specimens for immunofluorescence microscopy were received in Michelle's medium and stained using fluorescein isothiocyanate (FITC) conjugated polyclonal rabbit antisera against human IgG, IgM, IgA, C3c, C1q, kappa, and lambda. Control slides were also examined simultaneously. The trained pathologists at our hospital examined all renal biopsy specimens. Histopathology classification of lupus nephritis was performed using six classes (i.e., I to VI) as the criteria of the International Society of Nephrology and the renal pathology society (ISN/RPS) in 2003 revised in 2018 (16).

\subsection{Statistical Analyses}

We represented continuous data by the mean and standard deviation (with normal distribution data) or median and interquartile range (with non-normal distribution). In addition, categorical data using frequency and percentage. Receiver operating characteristic (ROC) curves were analyzed to predict severe active LN. Data analysis was administered using SPSS version 20.0 (Chicago, IL, USA). Statistical significance was considered when P-value $<0.05$.

\section{Results}

As shown in Table 1, SLE symptoms presented in patients with lupus nephritis were not considerable. The highest rate was skin lesion (57.6\%), followed by rheumatism (29.4\%) and the neurological lesion (10.6\%). The proportion of patients with a decrease in WBC was $17.6 \%$, while $75.3 \%$ of patients had anemia. The rate of patients with decreased serum albumin was $55.3 \%$, increased CRP was $25 \%$, increased Anti-dsDNA was 93.2\%, decreased C3 was $90.6 \%$, decreased C4 was 97.6\%, and positive antinuclear antibodies accounted for $81.8 \%$. Most patients had SLEDAI scores in moderate to very high activity.

As shown in Table 2, those with clear LN with edema, hypertension, and oliguria, accounting for $34.1 \%$ to $63.5 \%$ of all participants. Up to $76.5 \%$ of patients had an increase in UPCR $\geq 200 \mathrm{mg} / \mathrm{mmol}$. With the clinical syndromes of lupus nephritis, nephrotic syndrome accounted for 51.8\% of patients, 7.1\% of participants had kidney failure.

According to pathological morphology, most patients had an LN class of III and IV (37.6\% for each class), and only 7.1\% had an LN class of V and $17.6 \%$ class II. No patient was from a class I and VI (Table 3 ).

As shown in Table 4, the serum albumin decreased gradually, while the rate of nephrotic syndrome, UPCR, and SLEDAI score increased gradually from LN class II to V. The WBC, hemoglobin level, Anti-dsDNA, as well as eGFR, changed irregularly, and there was a statistically significant difference between the study groups $(\mathrm{P}<0.05)$.

Based on the Receiver operating characteristics (ROC) curve model (Figure 1), serum albumin, uPCR were appropriate predictors for severe, active LN (classes IV and V) (Serum albumin: AUC $=0.725, \mathrm{P}<0.001$, Cut-off value: 28.65 
Table 1. Clinical Characteristics and Laboratory Parameters of Pediatric Lupus Nephritis $(\mathrm{N}=85)^{\mathrm{a}}$

\begin{tabular}{|c|c|}
\hline Clinical Characteristics and Laboratory Parameters & Values \\
\hline Ages, y & $11.28 \pm 2.21$ \\
\hline \multicolumn{2}{|l|}{ Gender } \\
\hline Female & $73(85.9)$ \\
\hline Male & $12(14.1)$ \\
\hline \multicolumn{2}{|l|}{ BMI } \\
\hline Mean & $17.71 \pm 3.86$ \\
\hline Underweight & $15(17.6)$ \\
\hline Normal & $56(65.9)$ \\
\hline Overweight and Obesity & $14(16.5)$ \\
\hline \multicolumn{2}{|l|}{ Clinical features } \\
\hline Skin lesion & $49(57.6)$ \\
\hline Mouth erosion & $15(17.6)$ \\
\hline Rheumatism & $25(29.4)$ \\
\hline Neurological lesion & $9(10.6)$ \\
\hline Heart lesion & $2(2.4)$ \\
\hline \multicolumn{2}{|l|}{ Full blood count } \\
\hline $\mathrm{RBC}, \mathrm{T} / \mathrm{L}$ & $3.71 \pm 0.99$ \\
\hline WBC, g/L: Median & $6.62(4.59-10.01)$ \\
\hline$<4.0$ & $15(17.6)$ \\
\hline Hemoglobin, g/L: mean & $99.94 \pm 22.82$ \\
\hline Anemia & $64(75.3)$ \\
\hline Platelet, g/L & $219(149-320)$ \\
\hline Neutrophil/lymphocyte rate & $2.15(1.45-3.25)$ \\
\hline \multicolumn{2}{|l|}{ Immuno-biological data } \\
\hline Protein, g/L: Median & $61.7(51.95-71.05)$ \\
\hline$<56$ & $28(32.9)$ \\
\hline Albumin, g/L: Mean & $28.55 \pm 6.9$ \\
\hline$<30$ & $47(55.3)$ \\
\hline CRP, mg/L: Median & $1.43(0.32-5.54)$ \\
\hline$>5$ & $15(25)$ \\
\hline Anti-DsDNA, IU/L: Median & $378(110.2-1316)$ \\
\hline$<30$ & $5(6.8)$ \\
\hline$\geq 30$ & $68(93.2)$ \\
\hline C3, g/L: Median & $0.33(0.25-0.54)$ \\
\hline$<0.75$ & $77(90.6)$ \\
\hline$\geq 0.75$ & $8(9.4)$ \\
\hline C4,g/L: Median & $0.035(0.01-0.079)$ \\
\hline$<0.2$ & $83(97.6)$ \\
\hline$\geq 0.2$ & $2(2.4)$ \\
\hline Antinuclear antibodies $(+)$ & $63(81.8)$ \\
\hline \multicolumn{2}{|l|}{ SLEDAI score } \\
\hline Mean & $14.69 \pm 4.45$ \\
\hline Mild activity & $0(0)$ \\
\hline Moderate activity & $18(21.2)$ \\
\hline High activity & $52(61.2)$ \\
\hline Very high activity & $15(17.6)$ \\
\hline
\end{tabular}

Abbreviations: Anti-dsDNA, anti-double-stranded deoxyribonucleic acid; BMI body mass index; $\mathrm{CRP}$, $\mathrm{C}$ reactive protein; $\mathrm{C}$, complement component 3; $\mathrm{C} 4$, Complement component 4 ; RBC, red blood cell; SLEDAI, the systemic lupus erythematosus disease activity index; WBC, white blood cell.

${ }^{\mathrm{a}}$ Values are expressed as mean \pm SD, or median (\%), No. (\%).

\begin{tabular}{|c|c|}
\hline Some Characteristics of Lupus Nephritis & Values \\
\hline Edema & $54(63.5)$ \\
\hline Hypertension & $29(34.1)$ \\
\hline Oliguria & $62(61.2)$ \\
\hline \multicolumn{2}{|l|}{ Urine analysis } \\
\hline Hematuria $(+)$ & $69(81.2)$ \\
\hline Proteinuria (+) & $85(100.0)$ \\
\hline Leukocyte $(+)$ & $38(44.7)$ \\
\hline \multicolumn{2}{|l|}{ uPCR, mg/mmol } \\
\hline Median & $446.6(241.89-799.02)$ \\
\hline$<200$ & $20(23.5)$ \\
\hline$\geq 200$ & $65(76.5)$ \\
\hline \multicolumn{2}{|l|}{ Clinical syndromes } \\
\hline Nephritic syndrome & $35(41.1)$ \\
\hline Nephrotic syndrome & $44(51.8)$ \\
\hline Renal failure & $6(7.1)$ \\
\hline \multicolumn{2}{|l|}{ eGFR, $\mathrm{mL} / \mathrm{min} / 1.73 \mathrm{~m}^{2}$} \\
\hline Mean & $106.49 \pm 34.72$ \\
\hline$<60$ & $6(7.1)$ \\
\hline
\end{tabular}

Abbreviations: eGFR, estimated glomerular filtration rate; UPCR, urine protein/creatinine rate.

${ }^{\mathrm{a}}$ Values are expressed as mean $\pm \mathrm{SD}$, or median (\%), No. (\%).

Table 3. Pathological Morphology of Pediatric Lupus Nephritis $(\mathrm{N}=85)$

\begin{tabular}{ll}
\hline Classification & No. (\%) \\
\hline Class I: Minimal mesangial lupus nephritis & $0(0)$ \\
\hline Class II: Mesangial proliferative lupus nephritis & $15(17.6)$ \\
\hline Class III: Focal lupus nephritis & $32(37.6)$ \\
\hline Class IV: Diffuse Lupus Nephritis & $32(37.6)$ \\
\hline Class V: Membranous lupus nephritis & $6(7.1)$ \\
\hline Class VI: Advanced sclerotic lupus nephritis & $0(0)$
\end{tabular}

$\mathrm{g} / \mathrm{L}, \mathrm{Se}=68.4 \%, \mathrm{Sp}=70.2 \% . \mathrm{uPCR}: \mathrm{AUC}=0.725, \mathrm{P}<0.001$, Cutoff value: $558.56 \mathrm{mg} / \mathrm{mmol}, \mathrm{Se}=68.4 \%, \mathrm{Sp}=85.1 \%$ ).

\section{Discussion}

Lupus nephritis (LN) is a common manifestation among SLE patients, with a prevalence of $60 \%$ in adults and $80 \%$ in children. Up to $30 \%$ of patients progress to endstage renal disease (21). In our study, LN's clinical and laboratory characteristics are consistent with other studies conducted in various countries $(22,23)$. In addition, in the present study, the female-to-male ratio was 6.08/1, with diverse clinical manifestations of SLE. Patient with rheuma- 


\begin{tabular}{|c|c|c|c|c|c|}
\hline Characteristics & Class II (N = 15) & Class III (N = 32) & Class IV $(N=32)$ & Class V $(N=6)$ & $\mathbf{P}$ \\
\hline Ages, y & $12.27 \pm 1.33$ & $10.75 \pm 2.15$ & $11.44 \pm 2.24$ & $10.83 \pm 3.54$ & 0.157 \\
\hline \multicolumn{6}{|l|}{ Gender } \\
\hline Male & $14(93.3)$ & $26(81.3)$ & $28(87.5)$ & $5(83.3)$ & 0.716 \\
\hline Female & $1(6.7)$ & $6(18.8)$ & $4(12.5)$ & $1(16.7)$ & \\
\hline BMI & $17.18 \pm 4.58$ & $17.24 \pm 3.34$ & $17.91 \pm 3.35$ & $20.5 \pm 6.45$ & 0.269 \\
\hline \multicolumn{6}{|l|}{ FBC } \\
\hline WBC, $g / L$ & $6.73(4.73-12.13)$ & $5.7(3.56-9.33)$ & $5.96(4.62-8.75)$ & $14.02(8.39-17.35)$ & 0.043 \\
\hline Hemoglobin, g/L & $109.13 \pm 27.73$ & $100.25 \pm 18.99$ & $92.12 \pm 19.3$ & $117 \pm 32.49$ & 0.02 \\
\hline Platelet, g/L & $235(149-380)$ & $189.5(132.75-307)$ & $223(155-335.75)$ & $293(195.75-301.3)$ & 0.612 \\
\hline \multicolumn{6}{|l|}{ Immuno- } \\
\hline \multicolumn{6}{|l|}{ Biological data } \\
\hline Albumin, $\mathrm{g} / \mathrm{L}$ & $31.31 \pm 7.6$ & $30.71 \pm 6.21$ & $26.42 \pm 6.19$ & $21.53 \pm 4.57$ & 0.001 \\
\hline $\mathrm{CRP}, \mathrm{mg} / \mathrm{L}$ & $2.41(0.33-3.17)$ & $0.94(0.32-7.96)$ & $1.24(0.34-4.09)$ & $6.39(0.8-16.25)$ & 0.839 \\
\hline Anti-DsDNA, IU/L & $163(42.9-381.42)$ & $1200(225.95-2170)$ & $491.15(212.62-1507.75)$ & $96.85(67.85$ - 449.07) & 0.003 \\
\hline $\mathrm{C} 3, \mathrm{~g} / \mathrm{L}$ & $0.45(0.29-0.72)$ & $0.33(0.21-0.52)$ & $0.3(0.24-0.42)$ & $0.54(0.44-0.7)$ & 0.105 \\
\hline $\mathrm{C} 4, \mathrm{~g} / \mathrm{L}$ & $0.02(0.01-0.08)$ & $0.03(0.02-0.08)$ & $0.04(0.01-0.06)$ & $0.05(0.01-0.08)$ & 0.751 \\
\hline Edema & $7(46.7)$ & $15(46.9)$ & $18(56.3)$ & $4(66.7)$ & 0.74 \\
\hline Hypertension & $3(20)$ & $7(21.9)$ & $16(50)$ & $3(50)$ & 0.052 \\
\hline Nephrotic syndrome & $4(26.7)$ & $12(37.5)$ & $22(68.8)$ & $6(100)$ & 0.001 \\
\hline uPCR, mg/mmol & $296.22(90-446.6)$ & $339.39(121.6-537.6)$ & $641.28(389.8-993.3)$ & $1432.45(1028.7-3290.9)$ & $<0.001$ \\
\hline eGFR, $\mathrm{mL} / \mathrm{min} / 1.73 \mathrm{~m}^{2}$ & $121.83 \pm 28.6$ & $114.25 \pm 27.5$ & $87.76 \pm 33.52$ & $126.58 \pm 49.85$ & 0.001 \\
\hline SLEDAI score & $11.93 \pm 3.88$ & $14.97 \pm 4.82$ & $15.28 \pm 3.69$ & $17 \pm 5.47$ & 0.042 \\
\hline
\end{tabular}

tism and skin lesion accounted for the highest proportion ( $57.6 \%$ and $29.4 \%$, respectively), while the neurological lesion rate accounted for $10.6 \%$. The proportion of anemia is $75.3 \%$, and the average SLEDAI score is up to 14.69 point. Relevant immunological markers were encountered in the majority of cases, with $81.8 \%$ positive for antinuclear antibodies, 93.2\% increase in Anti-Ds-DNA $\geq 30 \mathrm{UI} / \mathrm{L}, 90.6 \%$ decrease in $\mathrm{C} 3<0.75 \mathrm{~g} / \mathrm{L}$, and $97.6 \%$ decrease in $\mathrm{C} 4<0.2 \mathrm{~g} / \mathrm{L}$. Local deposition of immune complexes, a consequence of classical activation of the complement, leads to decreased complement system protein levels $(14,24,25)$. Many studies reported that decreased $\mathrm{C} 3$ and $\mathrm{C} 4$ concentrations in plasma are related to the disease's active state $(14,26)$. According to the findings of the present study, patients with LN have severe clinical manifestations that demonstrate the mechanism of multiple organ damage of active SLE. Research on the pathogenesis of SLE showed an interaction between genetic and environmental factors, thereby im- pairing immune tolerance and initiating chronic autoimmune disease $(27,28)$. Many studies have shown that SLE clinical manifestations in children are often more severe and more susceptible to multiple organ damage than SLE in adults $(11,12,14,24)$.

Carrying out a study on 85 children with LN, we found that kidney lesions' clinical and subclinical symptoms were evident with $63.5 \%$ edema, $61.2 \%$ oliguria, and $34.1 \%$ hypertension. Urine analysis showed $81.2 \%$ positive hematuria and $100 \%$ positive proteinuria. Several studies indicated that hematuria and proteinuria are the most common kidney damage abnormalities ( 67 to $100 \%$ of SLE children) (11, 29). Various studies reported that hypertension accounts for 30 to $50 \%(11,22)$. In our study, the ratio of patients with nephrotic syndrome was $51.8 \%$, similar to Batinic et al. (30), but renal failure patients were $7.1 \%$, which is lower than the rate reported by Sevinc et al. (31). In patients with LN, the glomerulus is the most severely 


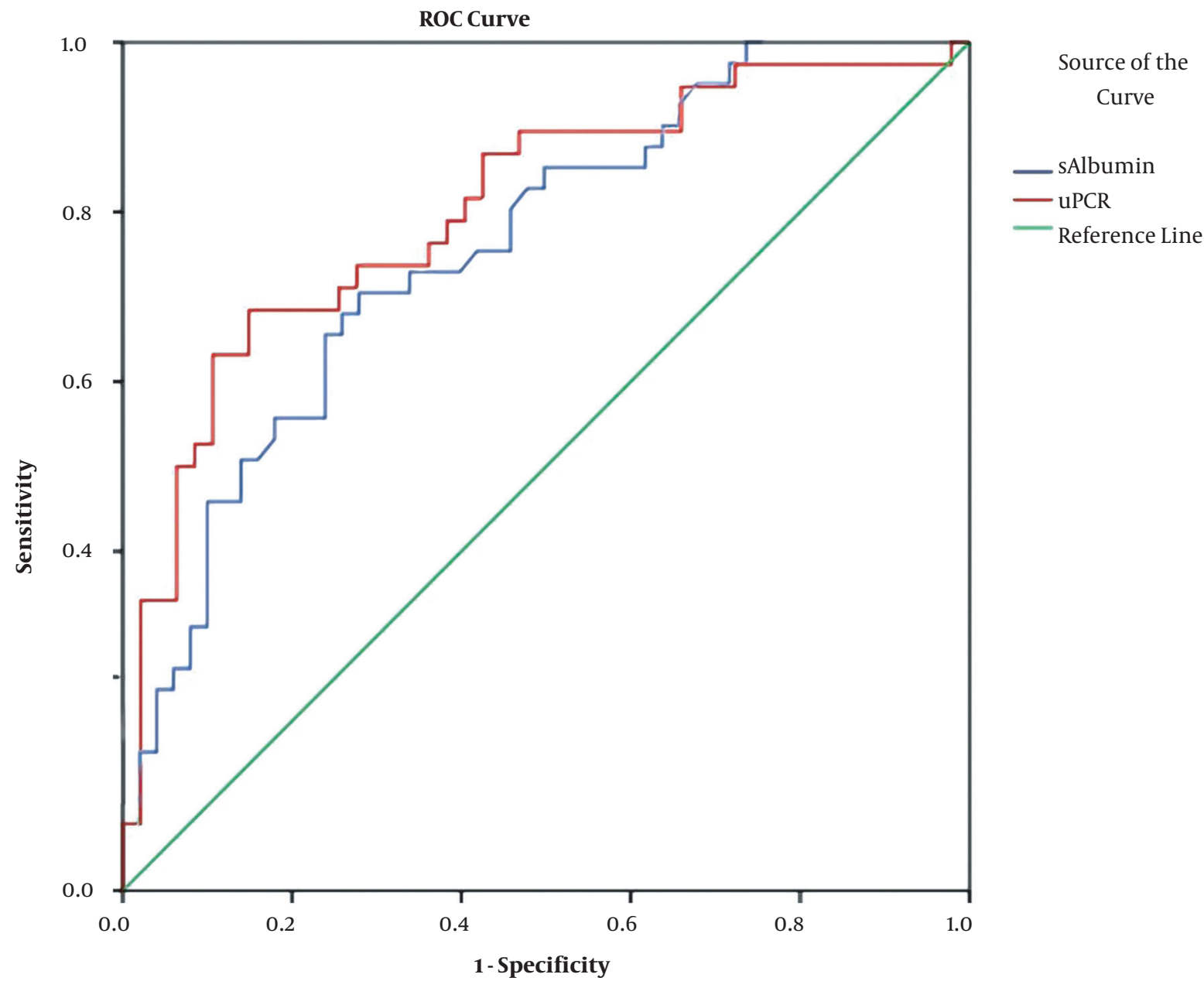

Figure 1. Receiver operating characteristics (ROC) curves for prediction of severe active LN (class IV and V)

damaged structure (14). Changes in membrane permeability are often related to proteinuria, local inflammation, glomerular hematuria, and decreased glomerular filtration (14). Regarding histopathological results, in the present study, the proportion of patients with class III and IV LN was $75.2 \%$, which is in line with the results of some other studies $(32,33)$. In LN patients, the production of systemic autoantibodies and complement disturbances are common. The immune complex deposited in glomeruli results in podocyte, mesangial cell, endothelial cell injury. When comparing the clinical and subclinical characteristics of LN classes, we found a gradual decline in the serum albumin concentration, the proportion of patients with nephrotic syndrome together with the median UPCR and SLEDAI score gradually increased from LN class II to V with
$\mathrm{P}<0.05$ (Table 4). Our results are consistent with some of the previously conducted studies and the pathogenetic mechanism of the kidney damage of $\operatorname{LN}(9,12,16,22,23)$.

A kidney biopsy is necessary to monitor the progression of LN. However, first, the patients must be hospitalized, and if the biopsy is available, techniques to diagnose pathological morphology should be provided immediately. Besides, those with severe diseases can not always undergo renal biopsies. An important question is that whether it is possible to use clinical manifestations or subclinical tests to preliminarily diagnose the class of LN to provide appropriate treatment immediately after hospitalization? We hypothesized that a decrease in serum albumin and an increase in uPCR could predict LN classes of IV and V. The results showed that both serum albumin 
and UPCR are valid for predicting LN classes pf IV and V, in which uPCR has a better value with AUC $=0.725, \mathrm{P}<0.001$, Cut-off value: $558.56 \mathrm{mg} / \mathrm{mmol}$, $\mathrm{Se}=68.4 \%, \mathrm{Sp}=85.1 \%$ (Figure 1). Although predictable, clinical practice shows that it is complicated to treat hypertension, massive proteinuria, and impaired function. LN classes of IV and V, and even class III must be treated even when the patient cannot undergo a renal biopsy $(8,34,35)$.

\subsection{Conclusions}

Serum albumin and uPCR were good predictors for severe, active LN.

\section{Footnotes}

Authors' Contribution: Conception and design: Ngoc Nguyen Thi, Dien Tran Minh, and Thang Le Viet. Acquisition of data: Huong Nguyen Thu, Nam Thai Thien, and Phuong Luong Thi. Analysis and interpretation of data: Diep Pho Hong, and Kien Nguyen Trung. Drafting the article and revising it: Ngoc Nguyen Thi, Dien Tran Minh. Final approval: Tien Tran Viet, Quyet Do, and Thang Le Viet.

Conflict of Interests: There were no authors' financial ties to products in the study or potential/perceived conflicts of interest available.

Ethical Approval: This study was approved by the Ethical Committee of National Children Hospital, Ha Noi, Viet Nam (no.: 1228/Q/BVNTW). All human research procedures followed the committee's ethical standards responsible for human experimentation (institutional and national) and the Helsinki Declaration of 1975, as revised in 2008.

Funding/Support: We did not receive any funding to conduct this research.

Informed Consent: Informed consent was obtained from all the participants.

\section{References}

1. Di Battista M, Marcucci E, Elefante E, Tripoli A, Governato G, Zucchi D, et al. One year in review 2018: systemic lupus erythematosus. Clin Exp Rheumatol. 2018;36(5):763-77. [PubMed: 30272543].

2. Rua-Figueroa Fernandez de Larrinoa I. What is new in systemic lupus erythematosus. Reumatol Clin. 2015;11(1):27-32. doi: 10.1016/j.reuma.2014.09.004. [PubMed: 25455719].

3. Rivas-Larrauri F, Yamazaki-Nakashimada MA. Systemic lupus erythematosus: Is it one disease? Reumatol Clin. 2016;12(5):274-81. doi: 10.1016/j.reuma.2016.01.005. [PubMed: 26922326].

4. Guery JC. Why Is Systemic Lupus Erythematosus More Common in Women? Joint Bone Spine. 2019;86(3):297-9. doi: 10.1016/j.jbspin.2018.12.004. [PubMed: 30584922].

5. Christou EAA, Banos A, Kosmara D, Bertsias GK, Boumpas DT. Sexual dimorphism in SLE: above and beyond sex hormones. Lupus. 2019;28(1):3-10. doi: 10.1177/0961203318815768. [PubMed: 30501463]. [PubMed Central: PMC6304686].
6. Abulaban KM, Brunner HI. Biomarkers for childhood-onset systemic lupus erythematosus. Curr Rheumatol Rep. 2015;17(1):471. doi 10.1007/s11926-014-0471-2. [PubMed: 25475594]. [PubMed Central: PMC4980820].

7. Bundhun PK, Kumari A, Huang F. Differences in clinical features observed between childhood-onset versus adult-onset systemic lupus erythematosus: A systematic review and meta-analysis. Medicine ( $\mathrm{Bal}$ timore). 2017;96(37). e8086. doi: 10.1097/MD.0000000000008086. [PubMed: 28906413]. [PubMed Central: PMC5604682].

8. Almaani S, Meara A, Rovin BH. Update on Lupus Nephritis. Clin J Am Soc Nephrol. 2017;12(5):825-35. doi: 10.2215/CJN.05780616. [PubMed: 27821390]. [PubMed Central: PMC5477208].

9. Thakur N, Rai N, Batra P. Pediatric Lupus Nephritis-Review of Literature. Curr Rheumatol Rev. 2017;13(1):29-36. doi: 10.2174/1573397112666160404124308. [PubMed: 27041086].

10. Smith EMD, Beresford MW. Urinary biomarkers in childhood lupus nephritis. Clin Immunol. 2017;185:21-31. doi: 10.1016/j.clim.2016.06.010. [PubMed: 27373868].

11. Levy DM, Kamphuis S. Systemic lupus erythematosus in children and adolescents. Pediatr Clin North Am. 2012;59(2):345-64. doi: 10.1016/j.pcl.2012.03.007. [PubMed: 22560574]. [PubMed Central: PMC3348509].

12. Sinha R, Raut S. Pediatric lupus nephritis: Management update World J Nephrol. 2014;3(2):16-23. doi: 10.5527/wjn.v3.i2.16. [PubMed: 24868499]. [PubMed Central: PMC4023399].

13. Lewandowski LB, Schanberg LE, Thielman N, Phuti A, Kalla AA, Okpechi I, et al. Severe disease presentation and poor outcomes among pediatric systemic lupus erythematosus patients in South Africa. Lupus. 2017;26(2):186-94. doi: 10.1177/0961203316660625. [PubMed: 27488473]. [PubMed Central: PMC5290292].

14. Bennett $M$, Brunner HI. Biomarkers and updates on pediatrics lupus nephritis. Rheum Dis Clin North Am. 2013;39(4):833-53. doi: 10.1016/j.rdc.2013.05.001. [PubMed: 24182857]. [PubMed Central: PMC4980821].

15. Dahlstrom O, Sjowall C. The diagnostic accuracies of the 2012 SLICC criteria and the proposed EULAR/ACR criteria for systemic lupus erythematosus classification are comparable. Lupus. 2019;28(6):778-82. doi: 10.1177/0961203319846388. [PubMed: 31046572]. [PubMed Central: PMC6537028].

16. Pinheiro SVB, Dias RF, Fabiano RCG, Araujo SA, Silva A. Pediatric lupus nephritis. J Bras Nefrol. 2019;41(2):252-65. doi: 10.1590/2175-8239-JBN2018-0097. [PubMed: 30465590]. [PubMed Central: PMC6699445].

17. National High Blood Pressure Education Program Working Group on High Blood Pressure in C; Adolescents. The fourth report on the diagnosis, evaluation, and treatment of high blood pressure in children and adolescents. Pediatrics. 2004;114(2 Suppl 4th Report):555-76. [PubMed: 15286277].

18. Schwartz GJ, Munoz A, Schneider MF, Mak RH, Kaskel F, Warady BA, et al. New equations to estimate GFR in children with CKD. J Am Soc Nephrol. 2009;20(3):629-37. doi: 10.1681/ASN.2008030287. [PubMed: 19158356]. [PubMed Central: PMC2653687].

19. Hahn BH, McMahon MA, Wilkinson A, Wallace WD, Daikh DI, Fitzgerald JD, et al. American College of Rheumatology guidelines for screening, treatment, and management of lupus nephritis. Arthritis Care Res (Hoboken). 2012;64(6):797-808. doi: 10.1002/acr.21664. [PubMed: 22556106]. [PubMed Central: PMC3437757].

20. Bertsias GK, Tektonidou M, Amoura Z, Aringer M, Bajema I, Berden $\mathrm{JH}$, et al. Joint European League Against Rheumatism and European Renal Association-European Dialysis and Transplant Association (EULAR/ERA-EDTA) recommendations for the management of adult and paediatric lupus nephritis. Ann Rheum Dis. 2012;71(11):1771-82. doi:10.1136/annrheumdis-2012-201940. [PubMed: 22851469]. [PubMed Central: PMC3465859]. 
21. Aljaberi N, Bennett M, Brunner HI, Devarajan P. Proteomic profiling of urine: implications for lupus nephritis. Expert Rev Proteomics. 2019;16(4):303-13. doi: 10.1080/14789450.2019.1592681. [PubMed: 30855196]. [PubMed Central: PMC6693508].

22. Singh S, Abujam B, Gupta A, Suri D, Rawat A, Saikia B, et al. Childhood lupus nephritis in a developing country-24 years' singlecenter experience from North India. Lupus. 2015;24(6):641-7. doi: 10.1177/0961203315570166. [PubMed: 25712249].

23. Samanta M, Nandi M, Mondal R, Hazra A, Sarkar S, Sabui T, et al Childhood lupus nephritis: 12 years of experience from a developing country's perspective. Eur J Rheumatol. 2017;4(3):178-83. doi 10.5152/eurjrheum.2017.16117. [PubMed: 29163999]. [PubMed Central: PMC5685279].

24. Malattia C, Martini A. Paediatric-onset systemic lupus erythematosus. Best Pract Res Clin Rheumatol. 2013;27(3):351-62. doi: 10.1016/j.berh.2013.07.007. [PubMed: 24238692].

25. Thurman JM, Nester CM. All Things Complement. Clin JAm Soc Nephrol. 2016;11(10):1856-66. doi: 10.2215/CJN.01710216. [PubMed: 27340286] [PubMed Central: PMC5053787].

26. Soliman S, Mohan C. Lupus nephritis biomarkers. Clin Immunol. 2017;185:10-20. doi: 10.1016/j.clim.2016.08.001. [PubMed: 27498110].

27. Nowling TK, Gilkeson GS. Mechanisms of tissue injury in lupus nephritis. Arthritis Res Ther. 2011;13(6):250. doi: 10.1186/ar3528. [PubMed: 22192660]. [PubMed Central: PMC3334648].

28. Flores-Mendoza G, Sanson SP, Rodriguez-Castro S, Crispin JC, Rosetti F. Mechanisms of Tissue Injury in Lupus Nephritis. Trends Mo Med. 2018;24(4):364-78. doi: 10.1016/j.molmed.2018.02.003. [PubMed: 29526595].

29. Font J, Cervera R, Espinosa G, Pallares L, Ramos-Casals M, Jimenez $S$, et al. Systemic lupus erythematosus (SLE) in childhood: analysis of clinical and immunological findings in 34 patients and comparison with SLE characteristics in adults. Ann Rheum Dis. 1998;57(8):4569. doi: 10.1136/ard.57.8.456. [PubMed: 9797549]. [PubMed Central: PMC1752720].

30. Batinic D, Milosevic D, Coric M, Topalovic-Grkovic M, Jelusic M, Turudic D. Lupus nephritis in Croatian children: clinicopathologic findings and outcome. Lupus. 2015;24(3):307-14. doi: 10.1177/0961203314563133. [PubMed: 25492940].

31. Sevinc E, Bilge I, Sirin A, Kilicaslan I, Nayir A, Oktem F, et al. Lupus nephritis in children: prognostic significance of clinicopathological findings. Nephron. 2001;87(2):118-26. doi: 10.1159/000045899. [PubMed: 11244305]

32. das Chagas Medeiros MM, Bezerra MC, Braga FN, da Justa Feijao MR, Gois AC, Reboucas VC, et al. Clinical and immunological aspects and outcome of a Brazilian cohort of 414 patients with systemic lupus erythematosus (SLE): comparison between childhoodonset, adult-onset, and late-onset SLE. Lupus. 2016;25(4):355-63. doi: 10.1177/0961203315606983. [PubMed: 26405022].

33. Srivastava P, Abujam B, Misra R, Lawrence A, Agarwal V, Aggarwal A. Outcome of lupus nephritis in childhood onset SLE in North and Central India: single-centre experience over 25 years. Lupus. 2016;25(5):547-57. doi: 10.1177/0961203315619031. [PubMed: 26637291].

34. Vachvanichsanong P, McNeil E. Pediatric lupus nephritis: more options, more chances? Lupus. 2013;22(6):545-53. doi: 10.1177/0961203313485490. [PubMed: 23629826].

35. Groot N, de Graeff N, Marks SD, Brogan P, Avcin T, Bader-Meunier B, et al. European evidence-based recommendations for the diagnosis and treatment of childhood-onset lupus nephritis: the SHARE initiative. Ann Rheum Dis. 2017;76(12):1965-73. doi: 10.1136/annrheumdis2017-211898. [PubMed: 28877866]. 